\title{
Investigation of the risk factors of preterm birth and infant mortality in Hungary - epidemiological and cost-effectiveness analyses
}

\author{
$\mathrm{PhD}$ Thesis
}

Csaba Nyári MSc

Supervisor: Tibor Nyári Ph.D

Department of Medical Physics and Informatics

Faculty of Medicine, University of Szeged Szeged

2014 


\section{Table of content}

Abbreviations

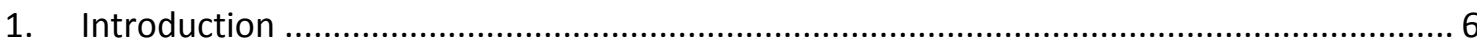

1.1. Trends in infant mortality rates in Hungary between 1963 and 2012 (Study I).......... 6

1.2. Chlamydia trachomatis infection and the risk of perinatal mortality in Hungary

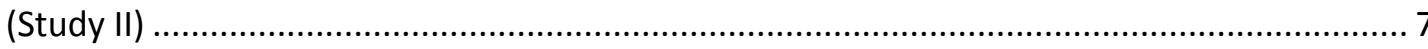

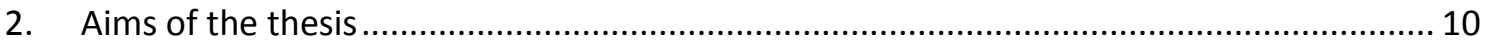

2.1. Trends in infant mortality rates in Hungary between 1963 and 2012 (Study I)........ 10

2.2. Chlamydia trachomatis infection and the risk of perinatal mortality in Hungary

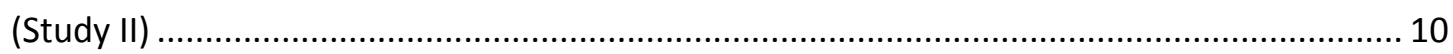

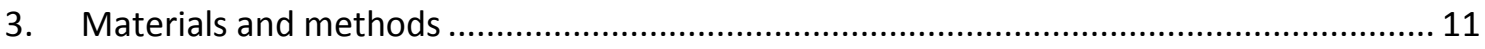

3.1. Trends in infant mortality rates in Hungary between 1963 and 2012 (Study I)........ 11

3.1.1. Investigation of annual trends and risk factors...................................... 11

3.1.2. Investigation of seasonal trends ......................................................... 12

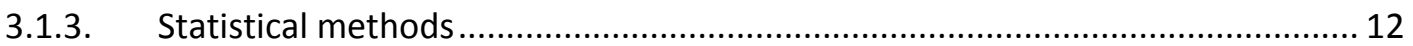

3.2. Chlamydia trachomatis infection and the risk of perinatal mortality in Hungary

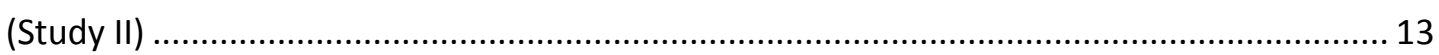

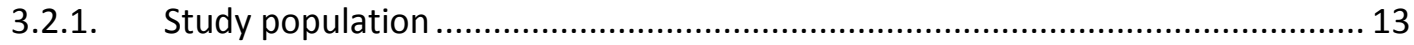

3.2.2. Data collection................................................................................. 13

3.2.3. Statistical analysis..................................................................... 13

3.2.4. The cost-effectiveness analysis ......................................................... 14

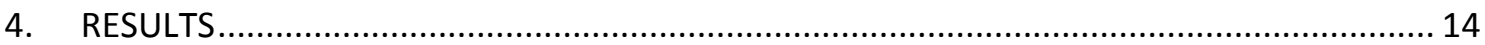

4.1. Trends in infant mortality rates in Hungary between 1963 and 2012 (Study I)........ 14

4.2. Chlamydia trachomatis infection and the risk of perinatal mortality in Hungary

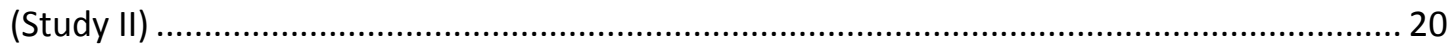

4.2.1. Characteristics of study subjects ..................................................... 20

4.2.2. Decision analysis........................................................................ 21

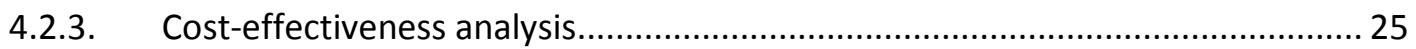

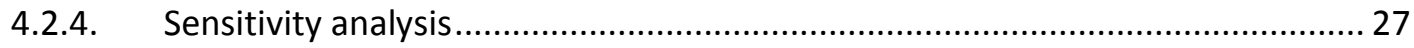

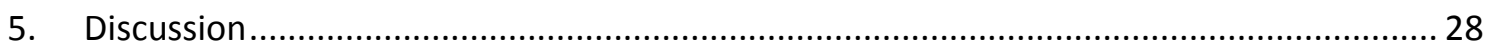

5.1. Trends in infant mortality rates in Hungary between 1963 and 2012 (Study I)........ 28

5.1.1. Strengths and weaknesses of the study .................................................. 28

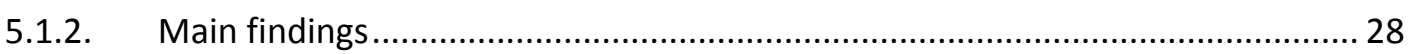

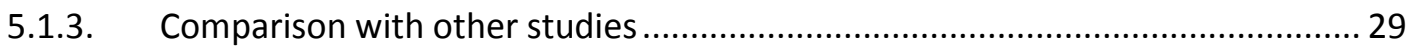


5.2. Chlamydia trachomatis infection and the risk of perinatal mortality in Hungary (

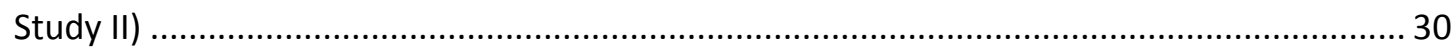

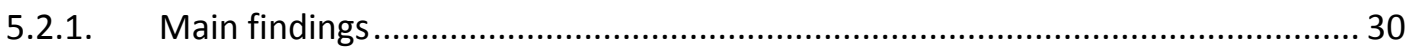

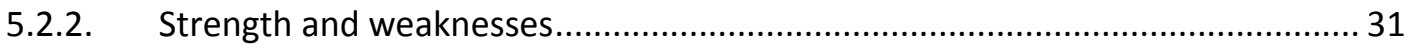

5.2.3. Comparison with other studies ...................................................................... 31

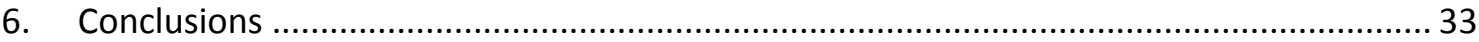

6.1. Trends in infant mortality rates in Hungary between 1963 and 2012 (Study I)......... 33

6.2. Chlamydia trachomatis infection and the risk of perinatal mortality in Hungary

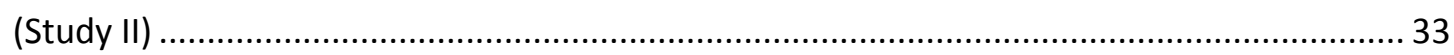

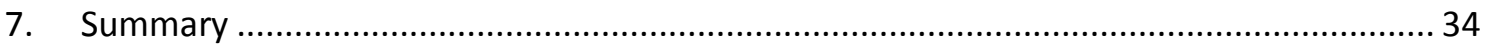

7.1. Trends in infant mortality rates in Hungary between 1963 and 2012 (Study I)......... 34

7.2. Chlamydia trachomatis infection and the risk of perinatal mortality in Hungary

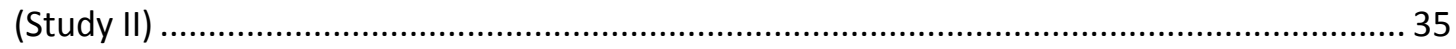

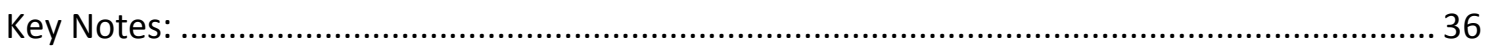

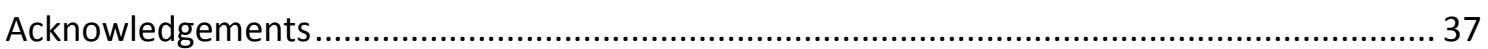

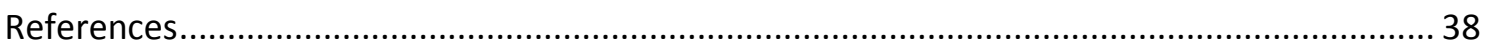




\section{ABBREVIATIONS}

CI

C. trachomatis

ELISA

HUF

IUGR

IVF

NICU

PID

PROM

PUA

RR

STD
Confidence intervals

Chlamydia trachomatis

Enzyme-linked immunosorbent assay

Hungarian forint

Intrauterine Growth Retardation

In vitro fertilization

Neonatal intensive care unit

Pelvic inflammatory disease

Premature rupture of membranes

Premature uterine activity

Relative risks

Sexually transmitted diseases 
This thesis is based on the following papers:

[I] Csaba Nyári, Tibor András Nyári, Richard J.Q, McNally. Trends in infant mortality rates in Hungary between 1963 and 2012. Acta Paediatrica, (In press) IF: 1.842

[II] Nyári T, Nyári C, Woodward M, Mészáros G, Deák J, Nagy E, Kovács L. Screening for Chlamydia trachomatis in asymptomatic women in Hungary. An epidemiological and cost-effectiveness analysis. Acta Obstet Gynecol Scand. 2001;80:300-306.IF: 1.206

Other publications of the candidate related to the thesis

[III] Nyári Tibor, Deák Judit, Nyári Csaba, Mészáros Gyula. Epidemiological investigation of the frequency of Chlamydia trachomatis infection and its risk factor [A Chlamydia trachomatis fertőzés gyakorisága és lehetséges rizikófaktorainak meghatározás epidemiológiai módszerekkel.] XXI. Neumann Kollokvium Veszprém, 1998 pp 167-169. (in Hungarian)

[IV] Nyári Csaba, Nyári Tibor. Investigation of cyclic trends using logistic regression [Ciklikus trendek vizsgálata logisztikus regresszióval.] XXVII. Neumann Kollokvium Szeged, 2014: pp 63-66.ISBN 978-963-369-040-0 (in Hungarian)

[V] Nyári Csaba, Nyári Tibor. Investigation of risk factors of stillbirth in Hungary [A késői magzati halálozás kockázati tényezőinek vizsgálata Magyarországon.] XXVII. Neumann Kollokvium Szeged, 2014: pp 149-152. ISBN 978-963-369040-0 (in Hungarian)

[VI] Ottóffy G, Szigeti E, Bartyik K, Nyári C, Parker L, McNally RJ, Nyári TA.Investigating the Relationship between Mortality from Respiratory Diseases and Childhood Acute Lymphoblastic Leukaemia in Hungary. Pathol Oncol Res. 2014 May 8. IF:1,806 


\section{INTRODUCTION}

According to the World Health Organization, the global number of deaths in the first year of life was 4.6 million, in 2013 [1]. The global infant mortality rate was 31.7 per 1,000 live births in 2013 [1]. About five times higher infant mortality was observed in Africa (60 per 1,000 live births) than in Europe (11 per 1,000 live births) [2]. Furthermore, $75 \%$ of infant deaths that occurred before one year of age were infants who were born prematurely [3].

Preterm birth (based on less than 37 completed weeks of gestation) is one of the most significant problems in perinatology. Beck et al [2] reported that the World Health Organization estimated that $9.6 \%$ births worldwide were preterm in 2005 which translated into about 12,9 million births definable as preterm [4]. Furthermore, about 0.5 million (6.2\%) and 8,198 (8.4\%) births were preterm in Europe and Hungary in 2005, respectively [4-5].

Various infections including Chlamydia trachomatis could cause preterm birth [6-7]. In pregnancy, Chlamydia trachomatis (C. trachomatis) may cause a wide range of serious complications, which include premature delivery, post-partum endometritis, ophthalmia neonatorum and neonatal pneumonia [8]. Furthermore, C. trachomatis is a major cause of neonatal morbidity and mortality [9-10]. Chlamydial infections of the genital tract are a problem worldwide. Despite the fact that chlamydial infection is relatively rare, the rate of genital chlamydial infection has increased in Hungary, since 2006 [11].

In this thesis, we present two epidemiological studies investigating i) the infant mortality in Hungary and ii) the role of maternal Chlamydia trachomatis in preterm birth.

\subsection{Trends in infant mortality rates in Hungary between 1963 and 2012 (Study I)}

Since 1981, the numbers of live births has been lower than the number of deaths in Hungary. A consequence of this trend is that the population fell below 10 million in Hungary in 2011 [5].

Infant mortality has been investigated in several countries and certain risk factors, including socio-economic, geographic and environmental, have been implicated [12- 
13]. Infant mortality rates have decreased in developed countries over the last two decades [14], including Hungary. Wang et al [1] reviewed the global infant mortality rate and reported an infant mortality of 4.6 per 1,000 live births in Hungary in 2013. Nevertheless, Hungary had the 2nd highest rate of infant mortality out of 24 European countries in the 2011 and 2012 tables produced by the Organization for Economic Cooperation and Development [4]. Figure 1 depicts the published European infant mortality rates per 1,000 live births in 2012. Only the mortality rate of 7.8 per 1,000 live births in Slovakia was higher than in Hungary.

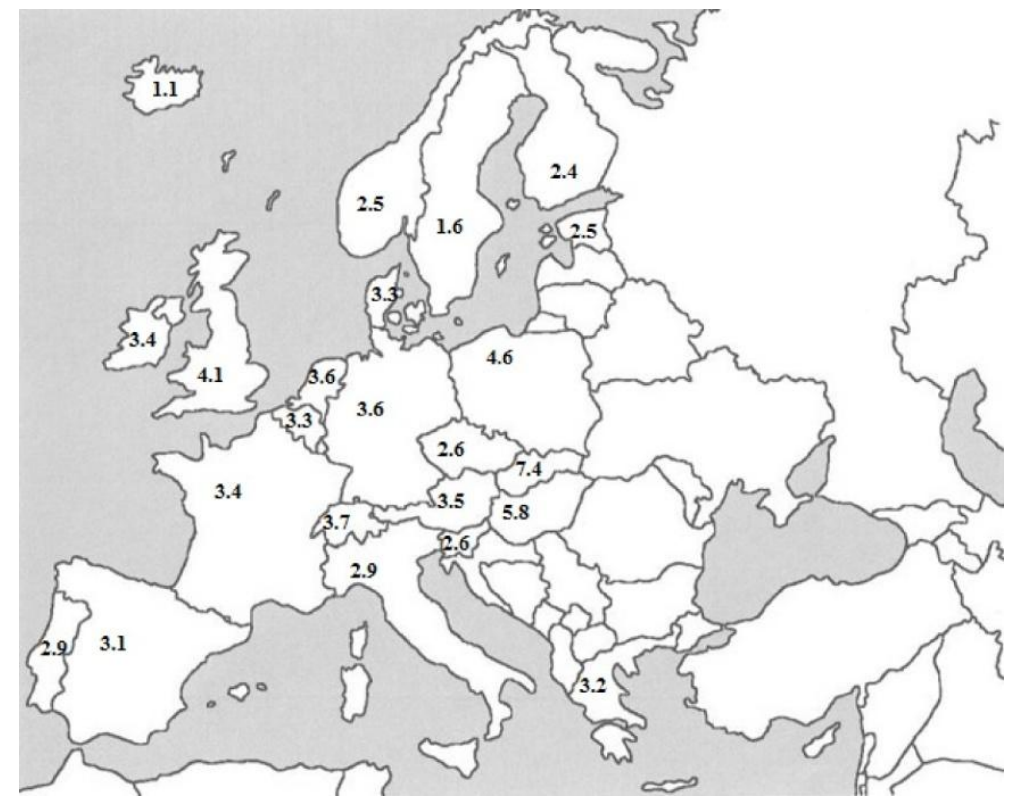

Figure 1. European infant mortality rates in 2013 [4].

However, in a recent paper, the Hungarian infant mortality rate of 4.6 per 1,000 live births in 2013 was slightly lower than the Central European average of 5.6 per 1,000 live births per year, but was higher than the reported Western European average of 3.2 per 1,000 live births [1]. In spite of these annual reported trends in Hungarian infant mortality, rates have not yet been investigated in any detail.

\subsection{Chlamydia trachomatis infection and the risk of perinatal mortality in Hungary (Study II)}

Halberstaedter and von Prowazek described the transmission of trachoma from humans to orangutans by experimental infection in Java in 1907 [15]. These newly discovered organisms were called Chlamydozoa. Similar inclusions were described subsequently in 
the conjunctival cells of babies with non-gonococcal ophthalmia neonatorum in cervical epithelium from some of their mothers and in urethral epithelium from male patients with non-gonococcal urethritis [16].

C. trachomatis infection is an STD that is common worldwide and have surpassed gonorrhoea as the number one in the United States (USA), the United Kingdom and the Scandinavian countries [17]. Sweden was the first country in the world to establish a national laboratory service for detecting chlamydial infections. In the Netherlands in 1987, about 90000 individuals were estimated to be infected with C. trachomatis [18]. The annual cost of chlamydial infection and its sequelae was estimated at $\$ 2.2$ billion in 1990 in USA [19].

Babies born vaginally to mothers with cervical chlamydial infection are at risk of becoming colonized or infected with an organism. Estimates of the risk are as high as $50 \%[7,18-19]$

Epidemiological evidence indicates that chlamydial infections of the genital tract are a global problem. Premature delivery is the most important perinatal problem in Hungary as Czeizel [20] and Orvos [21] have reported. In most cases the underlying cause is not known. A breakthrough in the prevention of preterm birth requires more data about the causes leading to premature uterine contractions.

The nationwide registration of $C$. trachomatis in Hungary has been performed since 1995 in ten clinical, hospital and public health laboratories. Chlamydia diagnostic methods have been carried out since 1985 in some research centres and hospital laboratories. The rate of $C$. trachomatis cases in the past decades are shown in Figure 2 [11]. 


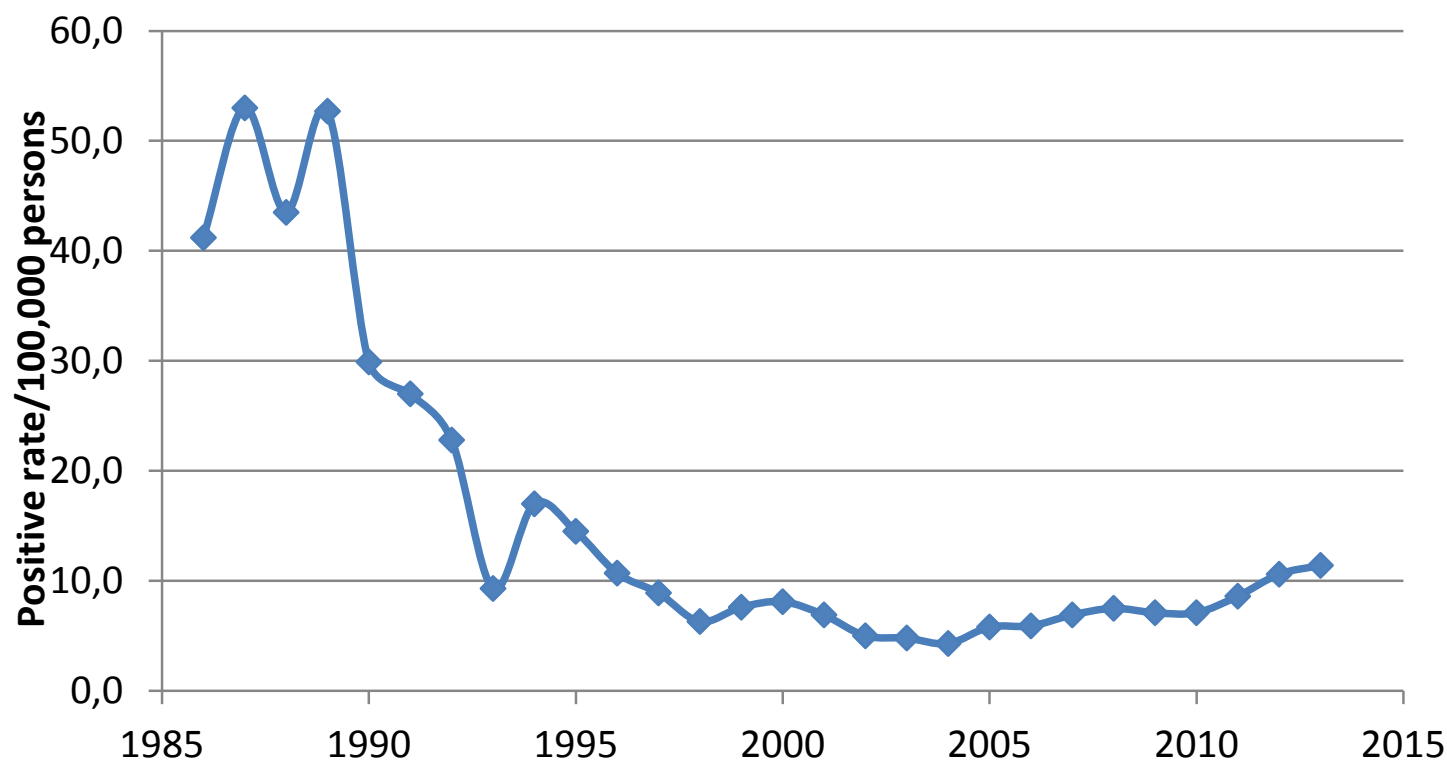

Figure 2. The rate of the detected genital chlamydial infection between 1986 and 2013 in Hungary [11]

A large number of anecdotal observations suggest that $C$. trachomatis infections may have a causative role in the origin of premature delivery [7, 22-23]. Consequently, a multicentre survey was carried out in order to determine the prevalence and risk factors for $C$. trachomatis infection in the pregnant population in Hungary [24-25]. The data set from the Hungarian survey was reanalysed in order to provide further information on the relationship between neonatal mortality and genital chlamydial infections and to estimate the frequency of these infections. 


\section{AIMS OF THE THESIS}

\subsection{Trends in infant mortality rates in Hungary between 1963 and 2012 (Study I)}

- In the longitudinal study, changes in infant mortality rates, annual trends and the effect of some possible risk factors related to deaths under the age of one year were investigated during the 50-year interval between 1 January 1963 and 31 December 2012, in Hungary.

- Furthermore, seasonality analyses of cyclic trends in infant mortality rates, were also carried out.

\subsection{Chlamydia trachomatis infection and the risk of perinatal mortality in Hungary (Study II)}

- In parallel with a study [24-25] to characterize the role of $C$. trachomatis in preterm birth, a multicenter survey was carried out in order to determine the prevalence and risk factors of $C$. trachomatis infection in the population of asymptomatic women.

- A cost-effectiveness analysis of chlamydial infection screening and its sequelae was carried out, to aid in developing screening criteria for genital chlamydial infection in women, in Hungary. 


\section{MATERIALS AND METHODS}

\subsection{Trends in infant mortality rates in Hungary between 1963 and 2012 (Study I)}

\subsubsection{Investigation of annual trends and risk factors}

Infant death was defined as death after live birth and before the age of one year. Data on the numbers of live births and infant deaths were obtained from the published nationwide population register of the Hungarian Central Statistical Office [5]. The 50year period between 1963 and 2012 was considered in this analysis. Annual birth and infant death data were available, with birth weight, sex, maternal age and maternal education, for both live births and infant death cases throughout the full 50-year period. Complete information was available for birth weight and sex. Maternal age was missing for $261(0.19 \%)$ of the records and maternal education was missing for $364(0.27 \%)$. Maternal age was also categorised using younger or older than 35-years-of-age. Maternal education was categorised as no primary school attended, primary school attended, vocational or secondary grammar school attended and higher education, which was regarded as the default group in the risk analyses. A birth weight of less than 2,500 $\mathrm{g}$ was regarded as a low birth weight.

The data concerning the cause of infant deaths were published annually by the Central Statistical Office. These data were classified according to the ICD10 codes. The main categories were: congenital malformation and certain conditions originating in the perinatal period, infectious and parasitic diseases, diseases of the nervous system and sense organs, diseases of the respiratory system, diseases of the digestive system and other cause of infant death, for example neoplasms, diseases of the circulatory system. The unknown or missing causes of deaths were officially classified into other causes of deaths [5]. 


\subsubsection{Investigation of seasonal trends}

The age of the infant death was categorised for neonatal (zero to 27 days) and postneonatal (28-364 days) mortality according to World Health Organization recommendations. The numbers of infant deaths were available at zero, one to six, seven to 13 and 14-27 days and at one to two, three to five and six to 11 months. Hence, the numbers of death in the early neonatal period (zero to six days) were calculated by adding the numbers of deaths that occurred within 24 hours and during one to six days after birth. Furthermore, the numbers of both monthly live birth and infant deaths, including the date of death, were available. However, monthly data on the cause of infant deaths were not available.

\subsubsection{Statistical methods}

Because the observed variance was greater than the mean of the death and birth variables, this is known as over-dispersion. Therefore the negative binomial regression method with the Huber-White estimator was applied to investigate the trends across annual rates and investigate the effect of possible risk factors - low birth weight, maternal education and sex - in relation to infant mortality [26]. Relative risks (RR) and 95\% confidence intervals (95\% CIs) were calculated. Trends in the annual number of infant deaths by cause of death were also investigated.

Data on the month of the death were aggregated over the study period. Cyclic trends in these monthly data were investigated using the Walter-Elwood method [27] and the logistic regression method using both sine and cosine functions [28]. This statistical test was used to retain the information on the connection of time periods by describing the seasonal pattern as one sine and one cosine function. These functions can be incorporated in a regression model that allows the investigation of single or double peaks of seasonality. Monthly cyclic trends (seasonality) were investigated in babies who died in the early neonatal period of zero to six days, by looking at babies who died within 24 hours after birth and babies who died during the first week after birth.

P-values of less than 0.05 were considered to be statistically significant. The Type I error was reduced using Bonferroni corrections. P-values were multiplied by the total 
number of significance tests. All analyses were performed using STATA Software version 9.0 (Stata Corp LP, College Station, Texas, USA)

\subsection{Chlamydia trachomatis infection and the risk of perinatal mortality in Hungary (Study II)}

\subsubsection{Study population}

The cross-sectional study started and terminated in 1995 in five different centers in three regions of Hungary: Western Hungary (Szombathely); Middle Hungary (Budapest and Szeged); Eastern Hungary (Miskolc and Nyíregyháza). The non-amplified nucleic acid hybridization method (PACE 2 Gen-Probe) was applied for the examination of $C$. trachomatis. Today, the sensitivity and specificity of this method are only $70 \%$ and $99 \%$ [29], respectively, and Bayes' theorem was therefore applied to assess the prevalence of the infection [30].

\subsubsection{Data collection}

The envisaged sample size was calculated by using Hsieh's formula [31]. The target population was women of reproductive age who were registered with a hospital, all of whom were asymptomatic as concerns genital infection. The sample was selected by using simple random sampling.

An interviewer-administered standardized questionnaire was completed, in which age, social and marital status and previous obstetrical history data were recorded. Data management was carried out with self-developed software.

\subsubsection{Statistical analysis}

Statistical analyses were performed with SPSSS for Windows (8.0 version) software packages. Independent predictors of chlamydial infection were assessed by using multiple logistic regression analysis. Odds ratios, as estimators of relative risks, together with their corresponding $95 \%$ confidence intervals (CI), were computed. A p value of less than 0.05 was taken to indicate a significant effect. 


\subsubsection{The cost-effectiveness analysis}

An incremental cost-effectiveness analysis was performed to compare the strategies of screening with the ELISA method (the sensitivity and specificity of this test are $70 \%$ and 99\%, respectively [29]) for the detection of C. trachomatis (strategy A), screening with use of the amplified Gen-Probe method (the sensitivity and specificity of this test are 92\% and 99\%, respectively) [29] for the detection of C. trachomatis (strategy B), and no application of screening methods (strategy C). Costs were based on local charges of the Hungarian Health Insurance [32].

\section{RESULTS}

\subsection{Trends in infant mortality rates in Hungary between 1963 and 2012 (Study I)}

During the 50-year interval, there were 6,336,976 live births $(3,247,936$ boys and $3,089,040$ girls) and 136,537 infant deaths (77,751 boys and 58,786 girls) in Hungary. There were 47,055 (34.5\%) within the first 24 hours of delivery, 87,757 (64.3\%) during the early neonatal period and $17,134(12.5 \%)$ during the late neonatal period. Thus $104,891(76 \%)$ of the infant deaths occurred during the first 28 days after birth. The number of normal and low birth weight infant deaths were 43,578 (32\%) and 92,959 $(68 \%)$, respectively.

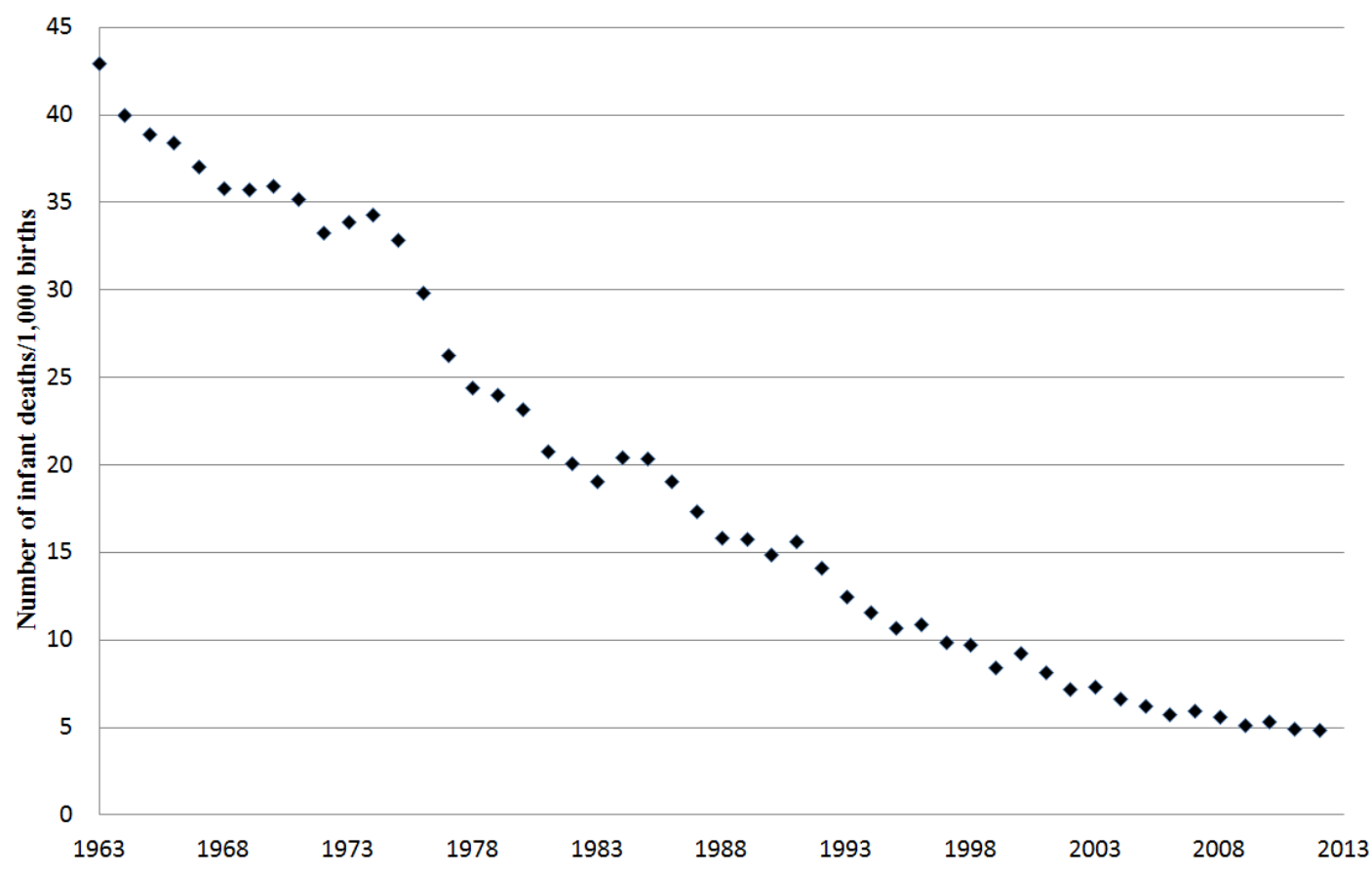

Figure 3. Infant mortality rate in Hungary between 1963 and 2012 
The annual infant mortality rate declined by $88.6 \%$ from the maximum of 42.9 per 1,000 births in 1963 to the minimum of 4.9 per 1,000 births in 2012 (Figure 3). There was a significant RR trend per annum of 0.954 (95\% CI $0.953-0.955$; $\mathrm{p}<0.001$ ). A similar decreasing trend was detected for the annual rate of early neonatal deaths with an annual RR of 0.944 (95\% CI 0.941-0.948; $\mathrm{p}<0.001)$.

A significantly increased risk of infant mortality was found in boys, with an RR of 1.23 (95\% CI 1.19-1.28, $\mathrm{p}<0.001)$, than girls. A significantly increased risk of infant death with an RR of 1.73 (95\% CI: $1.64,1.83$; $\mathrm{p}<0.001)$ was found in mothers over the age of 35 compared to mothers under this age.

The proportion of mothers in the no primary school completed group decreased from $32.3 \%$ to $7.2 \%$ during the 50 -year period. However, the proportion of mothers in the only primary school completed group decreased by only $24 \%$ from $56.8 \%$ to $32.8 \%$ in the last 20 years of the study. The 10-year interval aggregated numbers of infant deaths in the different maternal education groups are summarised in Table 1. The proportion of infant deaths was $5.7 \%$ in the group of mothers with longer education. In contrast, the overall proportion of mothers in the only primary school and no school groups were $52.2 \%$ and $20.6 \%$, respectively. Thus, the risk of an infant's death was higher in mothers with lower levels of education than those with higher levels of education $(\mathrm{RR}=1.31,95 \%$ CI $1.30-1.32, \mathrm{P}<0.001)$. For those whose mothers only completed secondary grammar or vocational school the RR was 1.28 (95\% CI 1.25-1.31). For those whose mothers only completed primary school the RR was 1.72 (95\% CI 1.671.75). For those whose mothers did not complete primary school the RR was 2.23 ( $95 \%$ CI 2.17-2.29). However, the highest risk of infant mortality with an RR of 20.2 (95\% CI 19.9-20.4 p<0.001) was observed in the low birth weight group compared with the normal birth weight group. Nevertheless, similar significantly declining $(\mathrm{p}<0.001)$ annual trends in infant mortality rates by sex, birth weight, maternal education and maternal were found in all subgroups as well as overall. 
Table 1. The numbers of infant deaths and maternal education in Hungary between 1963 and 2012. Mortality rates per 1,000 live births are given by time period and level of education.

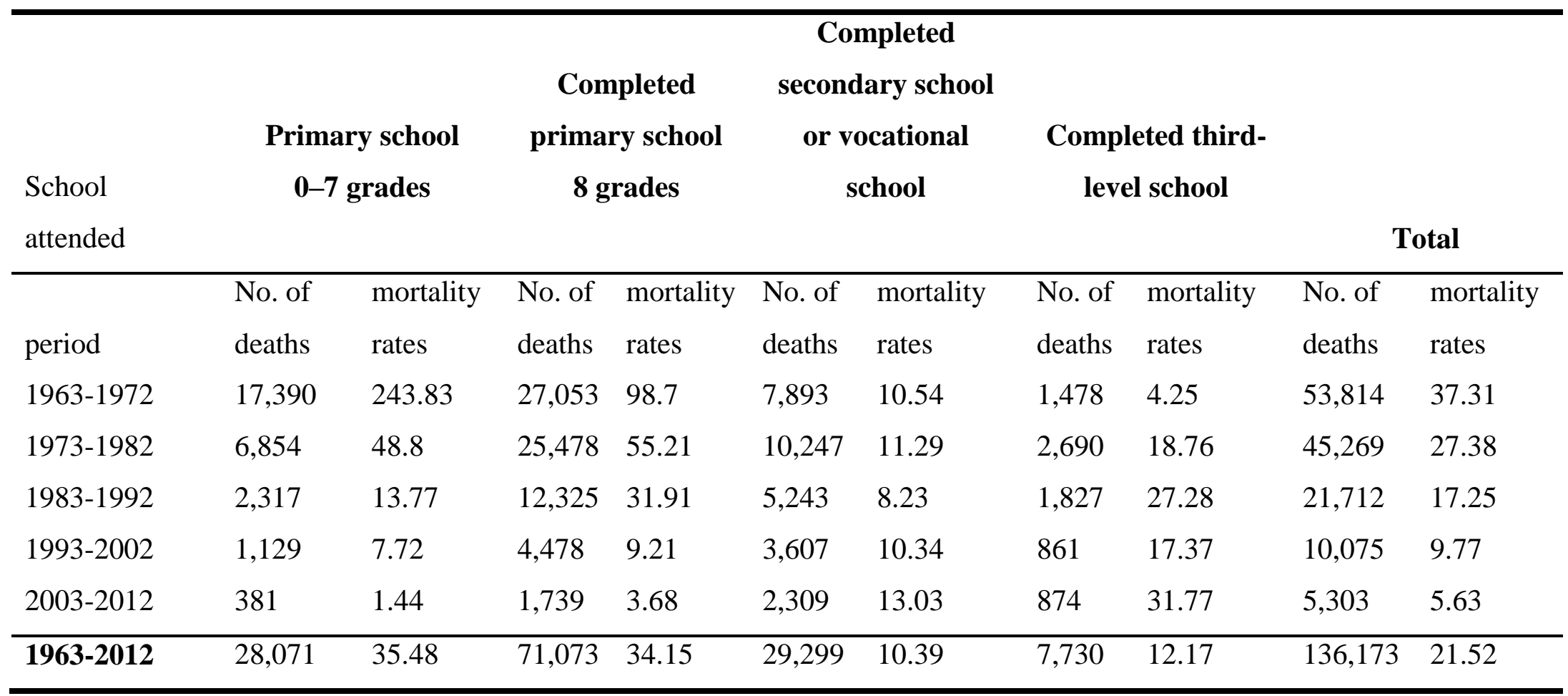


Table 2. Annual number of infant deaths by cause of death in Hungary between 1963 and $2012(\mathrm{~N}=136,537)$

\begin{tabular}{|c|c|c|c|c|c|c|c|}
\hline $\begin{array}{l}\text { Cause of } \\
\text { deaths }\end{array}$ & $\begin{array}{l}\text { Congenital } \\
\text { malformation and } \\
\text { certain conditions } \\
\text { originating in the } \\
\text { perinatal period }\end{array}$ & $\begin{array}{c}\text { Infectious and } \\
\text { parasitic } \\
\text { diseases }\end{array}$ & $\begin{array}{l}\text { Diseases of the } \\
\text { nervous system } \\
\text { and sense organs }\end{array}$ & $\begin{array}{l}\text { Diseases of the } \\
\text { respiratory } \\
\text { system }\end{array}$ & $\begin{array}{c}\text { Diseases of the } \\
\text { digestive } \\
\text { system }\end{array}$ & Other diseases & Total \\
\hline $\begin{array}{l}\text { ICD10 } \\
\text { codes }\end{array}$ & $\begin{array}{l}\text { Q00-Q99; } \\
\text { P00-P96 }\end{array}$ & A00-B99 & G00-G99 & J00-J99 & K00-K93 & & \\
\hline Trends* & $\begin{array}{c}0.956 \\
(0.954-0.958)\end{array}$ & $\begin{array}{c}0.960 \\
(0.953-0.967)\end{array}$ & $\begin{array}{c}0.946 \\
(0.942-0.950)\end{array}$ & $\begin{array}{c}0.918 \\
(0.912-0.925)\end{array}$ & $\begin{array}{c}0.899 \\
(0.891-0.907)\end{array}$ & & $\begin{array}{c}0.954 \\
(0.953-0.955)\end{array}$ \\
\hline Period & & & & & & & \\
\hline 1963-1972 & $41,673(38.1 \%)$ & $(43.0 \%)$ & $1,986 \quad(41.9 \%)$ & $5,836 \quad(50.2 \%)$ & $2,431 \quad(62.3 \%)$ & $1,367 \quad(24.6 \%)$ & $53,814(39.4 \%)$ \\
\hline 1973-1982 & $36,869(33.7 \%)$ & $276 \quad(22.8 \%)$ & $1,563 \quad(33.0 \%)$ & $3,724 \quad(32.0 \%)$ & $1,214 \quad(31.1 \%)$ & $1,628 \quad(29.3 \%)$ & $45,274(33.2 \%)$ \\
\hline 1983-1992 & $17,888(16.3 \%)$ & $233 \quad(19.2 \%)$ & $746 \quad(15.7 \%)$ & $1,466 \quad(12.6 \%)$ & $164 \quad(4.2 \%)$ & $1,230 \quad(22.2 \%)$ & $21,727(15.9 \%)$ \\
\hline 1993-2002 & $8,431 \quad(7.7 \%)$ & $139 \quad(11.5 \%)$ & $(6.3 \%)$ & $(4.2 \%)$ & $(1.6 \%)$ & $830 \quad(15.0 \%)$ & $10,249(7.5 \%)$ \\
\hline 2003-2012 & $4,646 \quad(4.2 \%)$ & $(3.5 \%)$ & $(3.1 \%)$ & $117 \quad(1.0 \%)$ & $(0.7 \%)$ & $(8.9 \%)$ & $5,473 \quad(4.0 \%)$ \\
\hline $1963-2012$ & $109,507(100 \%)$ & $1,212 \quad(100 \%)$ & $4,740 \quad(100 \%)$ & $11,629(100 \%)$ & $3,900 \quad(100 \%)$ & $5,549 \quad(100 \%)$ & $136,537(100 \%)$ \\
\hline
\end{tabular}

\footnotetext{
*Relative risk(RR) and $95 \%$ confidence interval $(95 \% \mathrm{CI})$
} 
Table 2 shows numbers of infant deaths together with the cause of death Similarly, the trends were significantly $(\mathrm{p}<0.001)$ decreased in annual infant mortality during the study period in the all cause of death categories as well as in all infant mortality during the study period (Table 2).

The monthly cyclic trends of mortality were investigated among all infants and, separately, in the groups of cases who died during the early neonatal period, within 24 hours after birth and during the first week after birth. The monthly numbers of babies who died within 24 hours of birth, infant deaths and early neonatal deaths used in the seasonal analyses are given in Table 3 .

Table 3. The monthly numbers of babies who died within 24 hours of birth, infant deaths and early neonatal deaths used in seasonal analyses.

\begin{tabular}{lllll}
\hline Months & $\begin{array}{l}\text { Numbers of babies } \\
\text { who died within } 24 \\
\text { hours of birth } \dagger\end{array}$ & $\begin{array}{l}\text { Numbers of early } \\
\text { neonatal deaths }{ }^{\dagger}\end{array}$ & $\begin{array}{l}\text { Numbers of all } \\
\text { infant deaths } \dagger\end{array}$ & $\begin{array}{l}\text { Numbers of } \\
\text { live births* }\end{array}$ \\
\hline January & 4,189 & 7,682 & 12,300 & 532,829 \\
February & 3,659 & 6,858 & 11,010 & 497,184 \\
March & 4,229 & 7,793 & 12,279 & 549,937 \\
April & 4,363 & 8,010 & 12,236 & 522,361 \\
May & 4,345 & 8,101 & 12,325 & 544,044 \\
June & 3,919 & 7,369 & 11,242 & 534,077 \\
July & 3,922 & 7,345 & 11,123 & 569,752 \\
August & 3,634 & 7,017 & 10,763 & 551,010 \\
September & 3,515 & 6,579 & 10,146 & 537,334 \\
October & 3,834 & 6,959 & 10,821 & 513,773 \\
November & 3,633 & 6,840 & 10,699 & 483,878 \\
December & 3,813 & 7,204 & 11,593 & 508,293 \\
\hline Total & 47,055 & 87,757 & 136,537 & $6,344,472 *$ \\
\hline
\end{tabular}

*The monthly numbers of births included stillbirths between 1963-1968 (6).

$\dagger$ The numbers based on date at death 
A significant cyclic trend in all infant mortality was revealed by the logistic regression model, with a peak of deaths during late February $(\mathrm{p}<0.001)$. Similarly, a significant cyclic trend was found with a peak of deaths during March both in the group of cases who died within 24 hours after birth $(\mathrm{p}<0.001)$ and in the group of cases who died during the early neonatal period $(\mathrm{p}<0.001)$, respectively.

In a sensitivity analysis, the Walter-Elwood method was applied to investigate the cyclic trends and this provided similar peaks to the logistic regression method. The peaks were in February for all infant deaths $(\mathrm{p}<0.001)$ and in March in both the group of cases who died within 24 hours after birth $(\mathrm{p}<0.001)$ and in the group of cases who died during the early neonatal period $(\mathrm{p}<0.001)$. Seasonality models with double peaks were also investigated using the logistic regression method. In double peak models neither the sine nor cosine variables were significant for all infants. However a significant $(\mathrm{p}=0.045)$ double peak in May and November was detected in the group of cases who died during the early neonatal period. The cyclic trends are depicted in Figure 4.

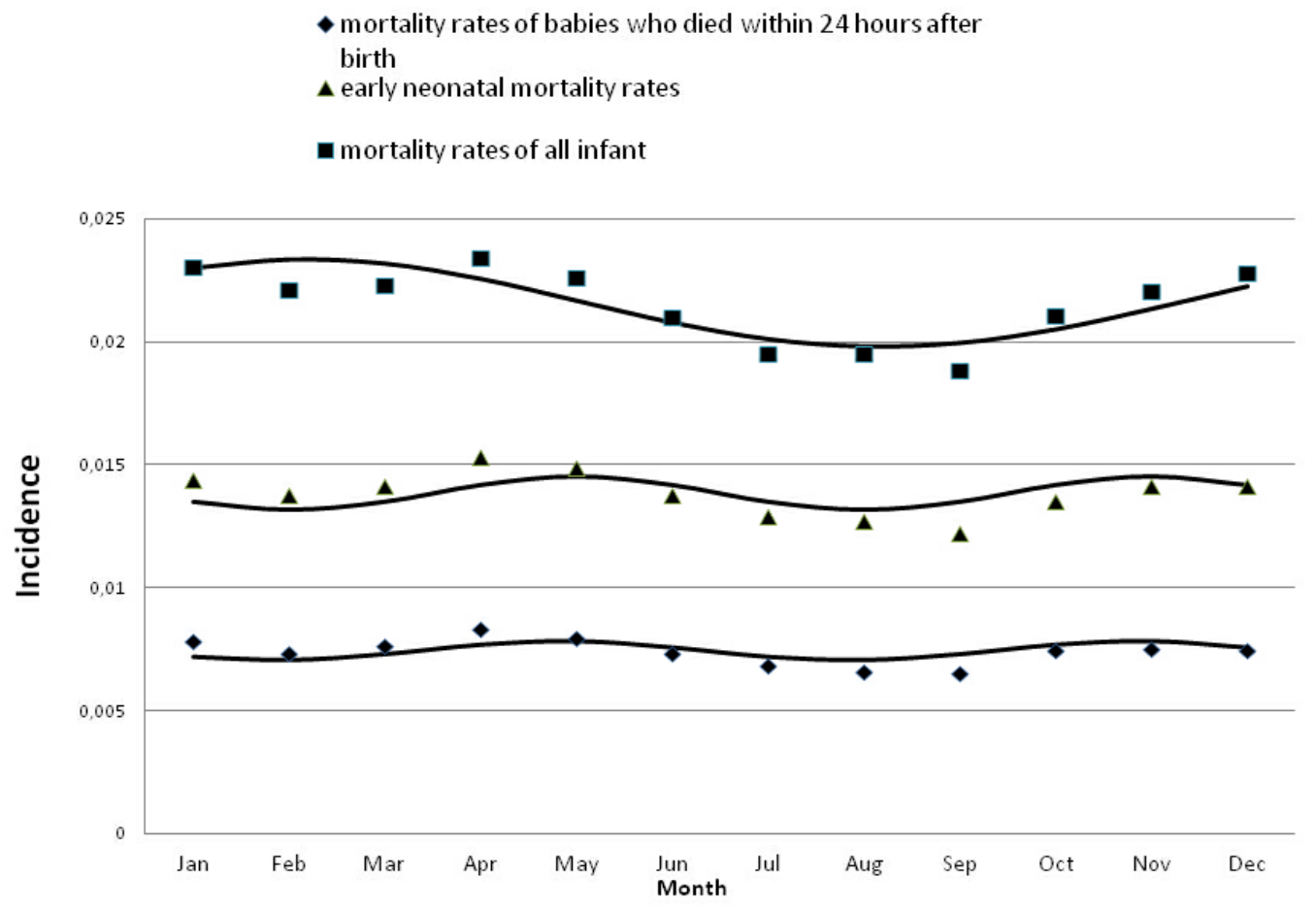

Figure 4. Seasonal variation in month of infant deaths 


\subsection{Chlamydia trachomatis infection and the risk of perinatal mortality in Hungary (Study II)}

\subsubsection{Characteristics of study subjects}

Accordingly, a total of 1300 pregnant women were examined for the occurrence of $C$. trachomatis. The overall average $C$. trachomatis infection rate was found to be $4.5 \%$, the data varying in the range $1.5-6.8 \%$ between the regions (Table 4).

Table 4. Risk factors for $C$. trachomatis infections among 1300 pregnant women. Odds ratios and $\mathrm{p}$ values from multivariate logistic regression analysis. An odds ratio of 1.0 indicates the reference category.

\begin{tabular}{|c|c|c|c|c|c|}
\hline & $\begin{array}{l}\text { No. } \\
\text { of } \\
\text { cases }\end{array}$ & $\begin{array}{l}\text { C. trachomatis- } \\
\text { positive }\end{array}$ & $\begin{array}{c}\text { Rate of } \\
\text { infection } \\
(\%)\end{array}$ & $\begin{array}{l}\text { Odds ratio } \\
(95 \% \mathrm{CI})\end{array}$ & $\begin{array}{l}\text { Probability } \\
\text { level of } \\
\text { significance }\end{array}$ \\
\hline Regions & & & & & $\mathrm{p}=0.002$ \\
\hline Eastern Hungary & 354 & 24 & 6.8 & $3.5(1.5-8.3)$ & \\
\hline Middle Hungary & 484 & 28 & 5.8 & 4.6(1.9-11.1) & \\
\hline Western Hungary & 426 & 7 & 1.5 & 1.0 & \\
\hline Age range(years) & & & & & $\mathrm{p}=0.014$ \\
\hline $15-19$ & 87 & 11 & 12.6 & $6.7(0.6-39.8)$ & \\
\hline $20-24$ & 410 & 25 & 6.1 & $2.7(0.4-21.2)$ & \\
\hline $25-28$ & 439 & 17 & 3.9 & $1.8(0.2-14.3)$ & \\
\hline $29-32$ & 206 & 2 & 1.0 & $0.4(0.1-4.4)$ & \\
\hline $33-38$ & 119 & 3 & 2.5 & $0.9(0.1-9.1)$ & \\
\hline $39 \leq$ & 39 & 1 & 2.6 & 1.0 & \\
\hline Marital status & & & & & $\mathrm{p}=0.0436$ \\
\hline Single & 38 & 5 & 13.2 & $3.3(1.1-9.6)$ & \\
\hline Divorced & 168 & 15 & 8.9 & $1.7(0.9-3.5)$ & \\
\hline Married & 1094 & 39 & 3.6 & 1.0 & \\
\hline
\end{tabular}

The difference between the average ages of the C. trachomatis-infected patients (23.8 (SD 5.7) years) and the non-infected women (27.1 (SD 5.8) years) was statistically significant $(\mathrm{p}<0.001)$. Certain potential risk factors relating to the infection were 
examined. As shown in Table 1, a young age, an unmarried status (single or divorced) and the regional difference (there was only a $1.5 \%$ rate of chlamydial infection in Western Hungary where the rate of unemployment has been lowest in the past few years) proved to be statistically significant predictors of the infection.

Furthermore, the group aged under 20 years displayed a very high rate of infection (12.6\%). However, with Bayes' theorem the overall estimated prevalence of chlamydial infection was $5.1 \%$, the assessed infection rates for the age groups varying in the range $0.6-16.9 \%$ (Table 5.).

Table 5. Observed and estimated C. trachomatis infection rates for the age groups.

\begin{tabular}{llccc}
\hline $\begin{array}{l}\text { Age } \\
\text { range } \\
\text { (years) }\end{array}$ & $\begin{array}{l}\text { No. } \\
\text { of }\end{array}$ & $\begin{array}{c}\text { C. trachomatis- } \\
\text { positive }\end{array}$ & $\begin{array}{c}\text { Observed rate of } \\
\text { infection }(\%)\end{array}$ & $\begin{array}{c}\text { Estimated rate of } \\
\text { infection }(\%)\end{array}$ \\
\hline $15-19$ & 87 & 11 & 12.6 & 16.9 \\
$20-24$ & 410 & 25 & 6.1 & 7.5 \\
$25-28$ & 439 & 17 & 3.9 & 4.2 \\
$29-32$ & 206 & 2 & 1.0 & 0.6 \\
$33-38$ & 119 & 3 & 2.5 & 2.3 \\
$39 \leq$ & 39 & 1 & 2.6 & 2.4 \\
Total & 1300 & 59 & 4.5 & 5.1 \\
\hline
\end{tabular}

\subsubsection{Decision analysis}

Decision analysis (Figure 5) was used to assess the potential outcome of chlamydial infection, and was modeled on an MS-Excel spreadsheet.

The major high-cost complications of chlamydial infection are pelvic inflammatory disease (PID), ectopic pregnancy, and tubal infertility. Women with untreated chlamydial infection were assumed to have a $20 \%$ risk of PID, with $10 \%$ of these cases necessitating hospitalization [33]. Ten percent of the women in whom PID developed were assumed to experience a subsequent ectopic pregnancy [34]. Tubal infertility was estimated in $20 \%$ of the women with PID [35]. Each infected woman was assumed to 
have one infected partner. Approximately $40 \%$ of men were assumed to have urethritis, $8 \%$ of whom required hospitalization because of epididymitis [36].

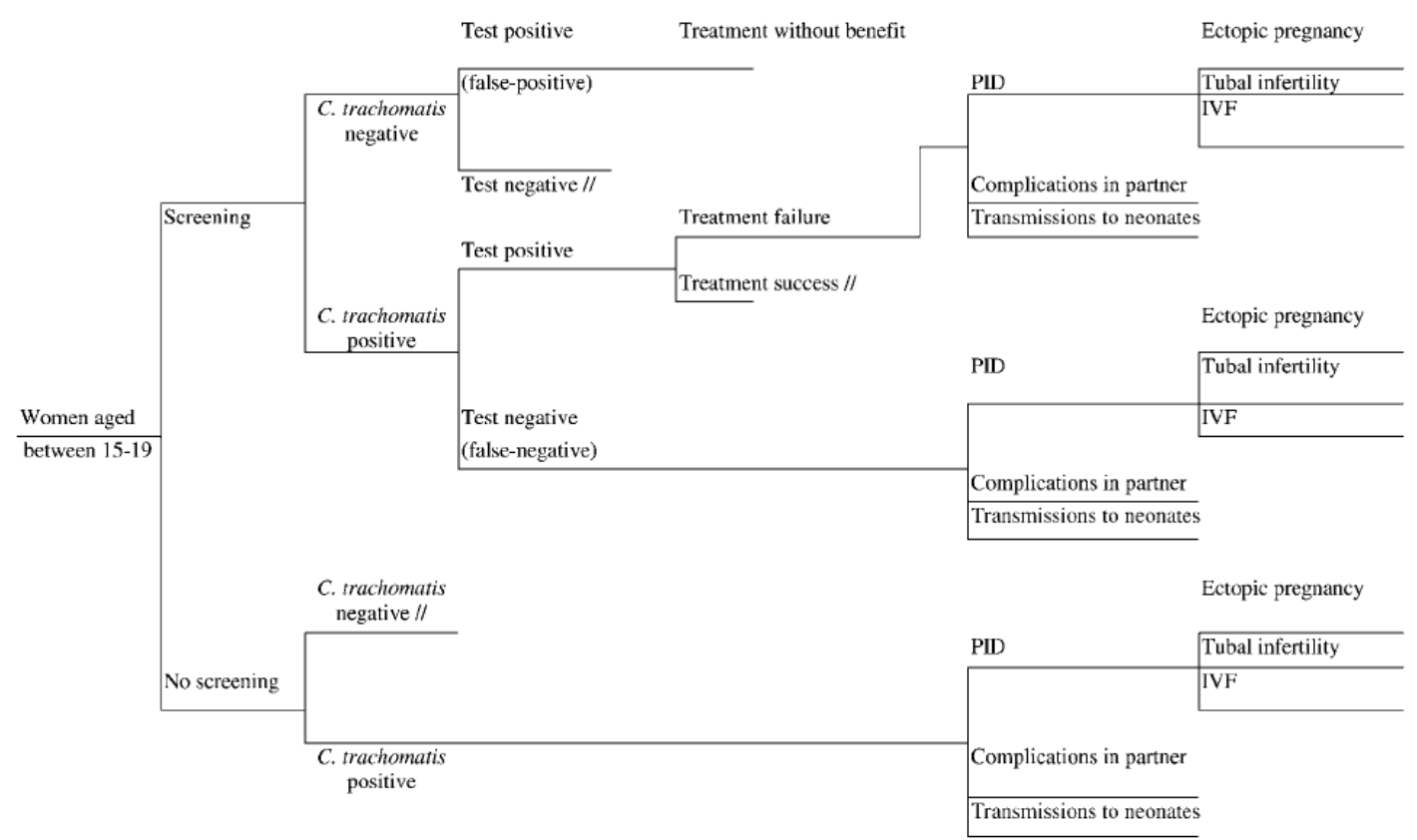

Figure 5. Decision tree for cost-effectiveness analysis of three screening strategy for female genital chlamydial infection.

The main complications in infants born to mothers infected with Chlamydia are conjunctivitis and neonatal pneumonia [37-40]. An earlier study of pregnant women, revealed that $17.1 \%$ of $C$. trachomatis-positive newborns were treated in neonatal intensive care units (NICU), and congenital pneumonia was identified in $7.1 \%$ of the newborns of Chlamydia-infected women [25,40].

Furthermore, a significant difference $(\mathrm{p}=0.001)$ was between the rate of premature uterine activity that occurred in the infected group (8.1\%), and the non-infected group (5.3\%). The overall perinatal mortality rate was $2.0 \%$ and a significantly higher ( $\mathrm{p}=0.042)$ mortality rate was detected in the group of $C$. trachomatis-positive patients than in the group of negative patients. In the group of perinatal death cases, the maternal C. trachomatis infection rate was $10.1 \%$.[41] 
Table 6. Conditional probabilities and costs used in cost-effectiveness analysis of C. trachomatis screening

$\begin{array}{ccccc}\text { Probability } & \text { Cost/ } & \text { Condition } & \text { Probability } & \text { Cost/case } \\ (\%) & \text { case }(\$) & & (\text { amp. Gen }) & (\$) \\ (\text { ELISA) } & \text { ELISA } & & & (\text { amp. Gen) }\end{array}$

\section{Screening and}

\section{treatment}

C. trachomatis

prevalence

Sensitivity of test

$\begin{array}{ll}12.6 & 7\end{array}$

12.6

13.9

Specificity of test

70

92

99

99

Effectiveness of the

95

treatment

Complications of

7

treatment

8 All treated

95

All infected and

7

Sequalae of untreated

\section{infection in women}

PID rate

20

Untreated

20

PID outpatient treatment

100

chlamydial infection

PID inpatient treatment

20

56

Symptomatic PID

100

77

Ectopic pregnancy

166 All PID

20

166

$10 \quad 357 \quad$ All PID

10

357

Tubal infertility

20

86 All PID

20

86

In vitro fertilization

$20 \quad 2,833 \quad$ All PID

20

2,833

Disease in male sex

partners

Transmission rate

Urethritis, epididymytis

40

15

Male with

40

22

(outpatient)

8

chlamydia

227 Symptomatic

8

urethritis

\section{Neonatal diseases}

\section{Birth rate}

Neonatal pneumonia

Preterm birth and

treatment in NICU

Treatment

Partner treatment
5

7

10

7

Maternal chlamydial infection

707 Maternal chlamydial infection
5

7

1,024

10

707

29

29 
Table 7. Number of cases of the three strategies (CT: C. trachomatis; NICU: neonatal intensive care unit)

\begin{tabular}{|c|c|c|c|c|c|}
\hline & $\begin{array}{c}\text { No } \\
\text { screening }\end{array}$ & $\begin{array}{c}\text { Screening } \\
\text { using } \\
\text { ELISA }\end{array}$ & $\begin{array}{c}\text { Prevented } \\
\text { cases }\end{array}$ & $\begin{array}{l}\text { Screening } \\
\text { using amp. } \\
\text { Gen-Probe }\end{array}$ & $\begin{array}{c}\text { Prevented } \\
\text { cases }\end{array}$ \\
\hline Total women & 400,000 & 400,000 & & 400,000 & \\
\hline Women tested & 0 & 400,000 & & 400,000 & \\
\hline Women with CT & 50,400 & 50,400 & & 50,400 & \\
\hline Women without CT & 349,600 & 349,600 & & 349,600 & \\
\hline True-positive & & 35,280 & & 46,368 & \\
\hline False-positive & & 3,496 & & 3,496 & \\
\hline True-negative & & 346,104 & & 346,104 & \\
\hline False-negative & & 15,120 & & 4,032 & \\
\hline Couple treated & & 38,776 & & 49,864 & \\
\hline Treatment complications & & 2,714 & & 3,490 & \\
\hline Women with CT (after) & 50,400 & 16,355 & 34,045 & 5,655 & 44,745 \\
\hline Women with PID & 10,080 & 3,271 & 6,809 & 1,131 & 8,949 \\
\hline $\begin{array}{l}\text { Outpatient treatment of } \\
\text { PID }\end{array}$ & 10,080 & 3,271 & 6,809 & 1,131 & 8,949 \\
\hline $\begin{array}{l}\text { Inpatient treatment of } \\
\text { PID }\end{array}$ & 2,016 & 654 & 1,362 & 226 & 1,790 \\
\hline PID surgery & 2,016 & 654 & 1,362 & 226 & 1,790 \\
\hline Infected male & 16,632 & 5,397 & 11,235 & 1,866 & 14,766 \\
\hline $\begin{array}{l}\text { Urethritis, epididymytis } \\
\text { outpatient }\end{array}$ & 6,653 & 2,159 & 4,494 & 746 & 5,906 \\
\hline Epididymytis, inpatient & 333 & 108 & 225 & 37 & 295 \\
\hline Ectopic pregnancy & 1,008 & 327 & 681 & 113 & 895 \\
\hline Tubal infertility & 2,016 & 654 & 1,362 & 226 & 1,790 \\
\hline Births to women with CT & 2,520 & 818 & 1,702 & 283 & 2,237 \\
\hline Neonatal pneumonia & 176 & 57 & 119 & 20 & 157 \\
\hline $\begin{array}{l}\text { Preterm birth and } \\
\text { treatment in NICU }\end{array}$ & 252 & 82 & 170 & 28 & 224 \\
\hline
\end{tabular}


The prevalence of $C$. trachomatis infection used in the analysis was $12.6 \%$. The costs of screening included the costs of tests, the therapy if tests were positive, the side-effects of therapy and empirical therapy of one male partner (Table 6). The cost of the diagnostic tests was $\$ 7$ and $\$ 13.9$ per test for the ELISA and Gen Probe methods, respectively. The cost of treating a woman twice a daily with doxycycline for 14 days was \$22 and \$29 for the ELISA and Gen-Probe methods (including a control test), respectively. We assumed that $3.5 \%$ of both women and men would have severe nausea and vomiting from doxycycline and would not be cured [42]. The birth rate was estimated as $5 \%$ per year. Table 7 displays the conditional probabilities and costs used in the cost-effectiveness analysis. Costs were based on local charges and were measured in US dollars (the exchange rate at that time was $1 \mathrm{USD}=243.4$ Hungarian forints). The analysis included only direct costs.

Sensitivity analysis was performed for outcomes in the model in order to determine how changes in estimated values affected the results and to identify "break-even" prevalence points [43].

Age-stratified demographical data on the female Hungarian population were available from the Hungarian National Statistical Office [5]. Approximately 400,000 women belonged in the group aged between 15 and 19 years on January 1, 1996.

\subsubsection{Cost-effectiveness analysis}

The most cost-effective strategy was strategy A (screening for $C$. trachomatis by using the ELISA method) (Table 8). Strategy B (screening for C. trachomatis by using GenProbe method) was slightly less cost-effective than neither testing nor treating (strategy C). Strategy A would eradicate a total of 34,045 chlamydial infections in 400,000 women with a chlamydial prevalence of $12.6 \%$. 
Table 8. Costs of each decision option

\begin{tabular}{lccc}
\hline & None & ELISA & GEN \\
\hline Testing & & $2,773,666.7$ & $5,547,333.3$ \\
Treatment for positive test & & $1,717,582.9$ & $2,900,173.3$ \\
Complications & $565,517.4$ & $183,510.4$ & $86,978.2$ \\
PID outpatient treatment & $334,098.2$ & $108,414.9$ & $37,485.8$ \\
PID inpatient treatment & $172,994.6$ & $56,136.8$ & $19,410.0$ \\
PID surgery & $101,945.8$ & $33,081.4$ & $16,614.9$ \\
Urethritis, epididymytis outpatient & $75,395.2$ & $24,465.7$ & $8,459.3$ \\
Epididymytis, inpatient & $359,953.4$ & $116,804.9$ & $40,386.8$ \\
Ectopic pregnancy & $5,712,000.0$ & $1,853,544.0$ & $640,886.4$ \\
Tubal infertility & $180,679.5$ & $58,630.5$ & $20,272.2$ \\
Neonatal pneumonia & $178,086.5$ & $57,789.1$ & $19,981.3$ \\
Preterm birth and treatment in NICU & $\mathbf{7 , 6 8 0 , 6 7 0 . 8}$ & $\mathbf{7 , 0 0 6 , 2 4 6 . 6}$ & $\mathbf{9 , 3 6 7 , 0 6 9 . 0}$ \\
\hline Total & & & \\
\hline
\end{tabular}

The results of the incremental cost-effectiveness analysis are shown in Table 9. Strategy A was more cost-effective than no screening, saving \$20 per case prevented. As compared with no screening, strategy B involved an extra cost of approximately $\$ 221$ for each case prevented, but prevented an additional 10,000 more cases relative to strategy A.

Table 9. Incremental cost-effectiveness of three screening strategies for C. trachomatis infection

\begin{tabular}{lcccc}
\hline Screening strategy & Total cost $(\$)$ & $\begin{array}{c}\text { Cases of } \\
\text { C. trachomatis } \\
\text { not detected }\end{array}$ & $\begin{array}{c}\text { Cases of } \\
\text { Crachomatis } \\
\text { prevented }\end{array}$ & $\begin{array}{c}\text { Cost-effectiveness } \\
\text { ratio } \\
(\$)\end{array}$ \\
\hline No screening & $7,680,670.8$ & 50,400 & & \\
ELISA & $7,006,246.6$ & 16,355 & 34,045 & $(20)$ \\
Gen-Probe & $9,367,069.0$ & 5,655 & 44,745 & 221 \\
\hline
\end{tabular}




\subsubsection{Sensitivity analysis}

With each assumption varied over a range of possible values, sensitivity analysis was performed. The policy of strategy B was less cost-effective than neither testing nor treating, unless certain conditions were satisfied. Table 10 displays the results of the sensitivity analysis. If the costs of the diagnostic test were less than or equal to $\$ 10.3$, or if the prevalence of infection in women were greater than $16.7 \%$, screening strategy B would be more cost-effective than neither testing nor treating. Additionally, if the conditional probability of tubal infertility exceeded the $25 \%$ used in the costeffectiveness analysis, screening method B would be cost-effective.

Table 10. One-way sensitivity analysis: breakpoints at which testing with the amplified Gen-Probe method for screening become more cost-effective than no testing.

\begin{tabular}{ll}
\hline & $\begin{array}{l}\text { Amplified } \\
\text { Gen probe }\end{array}$ \\
\hline Cost of test & $<\$ 10.3$ \\
Infection prevalence & $>16.7 \%$ \\
PID rate & $>24 \%$ \\
Probability of tubal infertility in an untreated woman & $>25 \%$ \\
\hline
\end{tabular}




\section{DISCUSSION}

\subsection{Trends in infant mortality rates in Hungary between 1963 and 2012 (Study I)}

\subsubsection{Strengths and weaknesses of the study}

Our population data were obtained from published tables. However a long study period of 50 years was used in the analyses, which allowed us to investigate trends in infant mortality rates. Furthermore, our data were obtained from civil registers, which could have been influenced by a certain simplification of categorisation. Additionally, minor changes occurred in the structure of the reported data during the 50-year interval of the study. Over-dispersion did not influence our results as the negative binomial regression method was applied in both risk estimation and the investigation of annual mortality trend.

In the seasonality, monthly cyclic trend analyses we used the Walter-Elwood method, which confirmed the findings of the logistic regression model since both gave similar results. Moreover, the longest study period was used in the seasonality analyses. The main shortcoming of this study is that we did not have information about the cause of infant death using the monthly frequencies to confirm the speculation of the infectious aetiology, although, a significant seasonal peak in February was found and the vast proportion $(75 \%)$ of deaths occurred in the neonatal period. The month of infant deaths were based on date at death. Therefore in the seasonal analyses the months of births and months of death are only the same in the group of babies who died within 24 hours after birth. There was a small shift between the months of births and months of death in the group of the early neonatal deaths. However, this shift was undetectable in the group of all infant deaths. Therefore, the double peaks analyses revealed no significant seasonality in the group of all infant deaths. Thus, the effect of infections around birth was described by double peaks models. Moreover, the application of Bonferroni correction reduced the probability of chance findings in our analyses.

\subsubsection{Main findings}

The annual infant mortality rate declined 10-fold from its maximum value in 1963 to the minimum value in 2012. Nevertheless, a significantly increased risk of infant mortality 
was observed in the low birth weight group compared with the normal birth weight group and lower maternal education also increased the risk of infant mortality.

A seasonal peak rate was found in February in the analyses that investigated the monthly cyclic trend of infant deaths and a peak mortality rate was revealed in March in the early neonatal mortality. Although, we did not have data on the age or birth weight of infant related to the monthly numbers of death, we might speculate that the significant peak of neonatal and infant mortality could be related to respiratory infections at the end of winter [28].

\subsubsection{Comparison with other studies}

Similar to other studies in Europe [44-48] the rates of both neonatal and infant death significantly decreased in Hungary during the 50-year study period. However, these other studies investigated shorter periods than our study. Nevertheless, the Hungarian infant mortality rate of 4.9 per 1,000 live births in 2011, was higher than the reported Western European infant mortality rate, which was 3.2 per 1,000 live births in 2011 [4].

Lin et al [49] investigated sex-specific risks and causes of mortality among low birth weight infants under one-year-of-age and found an RR of 8.99 in boys and an RR of 8.29 in girls. However, in our study a much higher RR of 20.2 for infant mortality was observed in the low birth weight group. Furthermore, a significantly increased RR of 1.23 for infant mortality was found in boys compared with girls.

Some studies described differences in infant mortality among geographic areas within a country [14] and Corchia and Orzalesi [50] reported a lower socio-sanitary level in the South compared to the North of Italy. We did not have data on socio-demographic characteristics, but we have found a strong negative correlation between the real income per person of the overall population and the rate of stillbirth in a previous study [51]. However, we investigated the relationship between maternal education and infant mortality and found that the lower education of mothers also increased the risk of infant deaths compared to the higher educated groups. This is the same as the study by Ko et al [52], who reported that maternal education levels were also inversely related to infant mortality. Arntzen et al [53] also reported a persistent inverse association between 
maternal educational level and neonatal death in a population-based study in the Nordic countries, but the published RRs were slightly lower than those were found in the present study. Similarly, Devlieger et al [54] found that increased infant mortality was associated with low levels of maternal education.

Finally, a peak in mortality rates was found in February in an analysis that investigated the monthly cyclic trend of infant deaths using both logistic regression and the WalterElwood methods. The later method was also applied in a study of analysis of seasonal variation of birth defects in Atlanta [55]. Seasonality of infant deaths was analysed by Hare et al [56] in relation to temperature changes. They reported that seasonal variations in the neonatal death rate were closely related to winter temperatures during the period 1921-1960. Similarly, our findings suggest that the significant peak of neonatal and infant mortality could have been related to respiratory infections at the end of winter. Furthermore, in a recent study, we have detected significantly increased risk of childhood acute lymphoid leukaemia among children under one year of age residing in areas around birth with higher levels of mortality from influenza [57]. However, further cohort studies should be carried out to investigate this hypothesis, using detailed individual data including age at death, month of death, sex and birth weight.

\subsection{Chlamydia trachomatis infection and the risk of perinatal mortality in Hungary (Study II)}

\subsubsection{Main findings}

A multicenter survey was carried out in order to determine the prevalence and risk factors of $C$. trachomatis infection in the population of asymptomatic women in Hungary. The overall average prevalence of $C$. trachomatis cases among 1,300 pregnant women was $4.5 \%$, with an increase to $5.1 \%$ on the basis of the Bayesian approach. There were significant differences in the proportions of chlamydial infection in the different regions, and also in the different age groups and the different family status groups. The group aged under 20 years displayed $12.6 \%$ rate of infection.

Using this rate in the cost-effective analysis, the most cost-effective strategy was strategy A: screening for $C$. trachomatis by using the ELISA method, however, strategy 
$\mathrm{B}$ is the recommended method of screening since this strategy can prevent an additional 10,000 more cases relative to strategy A.

\subsubsection{Strength and weaknesses}

This study was carried out to determine the prevalence and risk factors of $C$. Trachomatis in the population of asymptomatic women, however, the role of $C$. Trachomatis in preterm birth was not investigated here. We adapted these findings from the parallel study which described the relationship between maternal chlamydial infection and preterm birth in Hungary [24,40-41]. However, our study was the first to investigate the cost-effectiveness of strategies to screen for C. trachomatis in Hungary. It is necessary to estimate the true prevalence of $C$. trachomatis infection because detection and treatment of asymptomatic cases have a major impact on the incidence of chlamydial infection, these asymptomatic individuals being an active source of new infections [58-60]. In epidemiology, certain methods have been suggested to correct for measurement error [61]. In our analyses, a Bayesian approach was employed to correct measurement errors.

Nevertheless, a cost-effectiveness study was carried out in 2008 [62]. The costs used in cost-effectiveness analysis were updated and reanalysed and similar findings were observed for the screening strategies of cervical infection with $C$. trachomatis as in the very first study.

\subsubsection{Comparison with other studies}

A precise estimation of the prevalence of $C$. trachomatis infection is important in costeffectiveness analysis. In developed countries, the debate on Chlamydia control has centered on the cost-effectiveness of different approaches for identifying infected persons [63-68]. It has been concluded that, among women, case findings involving the use of laboratory tests is cost-effective at $C$. trachomatis prevalence rates as different as $6 \%$ to $16 \%$. In the cost-effectiveness analysis, we accounted for asymptomatic PID and included direct costs only for outcomes that developed in women with untreated chlamydial infection. The most cost-effective strategy was strategy A (screening for $C$. trachomatis by using the ELISA method). Strategy B (screening for C. trachomatis by using the amplified Gen-Probe method) was slightly less cost-effective than neither 
testing, nor treating (strategy $\mathrm{C}$ ), but can prevent an additional 10,000 more cases relative to strategy $\mathrm{A}$. When the estimated rate of infection of $16.9 \%$ in the age group under 20 years was taken into consideration, the established rate proved higher than that calculated in sensitivity analysis, and strategy B is therefore the recommended method of screening.

The advent of available, simple and inexpensive screening tests has increased the possibility of routine prenatal screening for C. trachomatis. We conclude that age-based screening with amplified Gen-Probe assays (combined with treatment of positive patients and partner notification) is the preferred screening strategy for women in Hungary. Since the majority of the $C$. trachomatis-infected cases were asymptomatic, we suggest to use amplified Gen-Probe assays for screening of all women with evidence of mucopurulent cervicitis and all women of age group between 15-19 years who have had sexual intercourse. We also recommend testing women between 20 to 24 years of age who have not consistently used barrier contraception or have had a new sex partner or more than one sex partner during the past six months and testing the pregnant population before delivery and before artificial abortion and after spontaneous abortion. Furthermore, extension of the screening procedure to test all pregnant women for transplacentally or perinatally transmitted diseases comprises an important part of obstetrical care [69-72] considering that the rate of genital chlamydial infection has been increasing in Hungary since 2006. 


\section{CONCLUSIONS}

\subsection{Trends in infant mortality rates in Hungary between 1963 and 2012}

(Study I)

In this study, a number of risk factors and trends were investigated in relation to infant mortality using well established statistical methods. We found seasonal effects related to infant and early neonatal mortality, with peaks in February and March, when the rate of respiratory infections is the highest in Hungary. These findings could prove useful in preventive strategies, but further cohort studies should be carried out to investigate this hypothesis using detailed individual data.

\subsection{Chlamydia trachomatis infection and the risk of perinatal mortality in Hungary (Study II)}

The advent of available, simple and inexpensive screening tests has increased the feasibility of routine prenatal screening for C. trachomatis. We conclude that age-based screening with amplified Gen-Probe assays (combined with treatment of positive patients and partner notification) is the preferred screening strategy for women in Hungary. Furthermore, extension of the screening procedure to test all pregnant women for diseases that can be transmitted transplacentally or perinatally comprises an important part of obstetrical care.

The introduction of the screening of $C$. trachomatis can reduce the sequelae of untreated C. trachomatis infections and can detect other STDs. This prevention may reduce the number of expensive diagnostic and therapeutic methods 


\title{
7. SUMMARY
}

\subsection{Trends in infant mortality rates in Hungary between 1963 and 2012 (Study I)}

\begin{abstract}
Aim: A longitudinal study was used to investigate annual and seasonal death trends for infants of less than one-year-of-age in Hungary between 1963 and 2012 and analysed commonly accepted risk factors.
\end{abstract}

Methods: Data on the numbers of live births and infant deaths were obtained from the published nationwide population register. Negative binomial regression was applied to investigate the yearly trends in rates and also the effect of possible risk factors - low birth weight, maternal education and sex - on infant mortality. Cyclic trends were investigated using logistic regression.

Results: Annual infant mortality declined significantly $(\mathrm{p}<0.001)$ from 42.9 to 4.9 per 1,000 live births per year during the study period and significantly increased $(p<0.001)$ in the low birth weight group and lower maternal education groups. A significant $(\mathrm{p}<0.001)$ cyclic trend in mortality was revealed, with a peak in deaths in late February for all infants and a double peak, in May and November, in the group of cases who died during the early neonatal period.

Conclusion: This Hungarian study suggests that there was a significant seasonal effect on neonatal and infant mortality at the end of winter between 1963 and 2012. We speculate that this may have been related to respiratory infections. 


\subsection{Chlamydia trachomatis infection and the risk of perinatal mortality in Hungary (Study II)}

Aim: A multicenter survey was carried out in 1995 in order to determine the prevalence and risk factors of Chlamydia trachomatis infection in the population of asymptomatic women in Hungary and to carry out a cost-effectiveness analysis to screen for chlamydial infection in women with asymptomatic genital infections.

Methods: The non-amplified nucleic acid hybridization method (PACE 2 Gen-Probe) was applied for the examination of $C$. trachomatis. Today, the sensitivity and specificity of this method are only $70 \%$ and $99 \%$, respectively, and Bayes' theorem was therefore applied to assess the prevalence of the infection. Multiple logistic regression analysis was performed to differentiate the risk factors of chlamydial infections.

Results: The overall average prevalence of Chlamydia trachomatis cases among 1300 pregnant women was $4.5 \%$. However, with Bayes' theorem the overall estimated prevalence of chlamydial infection was $5.1 \%$. There were significant differences in the proportions of chlamydial infection in the different regions, and also in the different age groups and the different family status groups.

Using results of the epidemiological study a cost-effectiveness analysis was carried out. When the estimated rate of infection of $16.9 \%$ in the age group under 20 years was taken into consideration, the established rate proved higher than that calculated in sensitivity analysis, and strategy screening for chlamydial infection by using the amplified Gen-Probe method is therefore the recommended method of screening.

Discussion: We conclude that age-based screening with amplified Gen-Probe assays (followed by treatment of positive patients and partner notification) is the preferred screening strategy for women in Hungary. 


\section{KEY NOTES:}

- This study investigated annual and seasonal death trends for infants of less than one-year-of-age in Hungary from 1963-2012.

- The highest risk of infant mortality with an RR of 20.2 (95\% CI 19.9-20.4 $\mathrm{p}<0.001$ ) was observed in the low birth weight group compared with the normal birth weight group.

- Annual infant mortality declined significantly during the study period and significantly increased in the low birth weight and lower maternal education groups.

- A significant cyclic trend in mortality was revealed, with a peak in deaths in late winter for all infants and peaks in May and November for early neonatal infants.

- Young age, unmarried status (single or divorced) and region proved to be statistically significant predictors of the genital chlamydial infection.

- Age-based screening with amplified Gen-Probe assays (combined with treatment of positive patients and partners) is the preferred screening strategy of Chlamydia trachomatis for women in Hungary. 


\section{ACKNOWLEDGEMENTS}

I am greatly indebted to Tibor Nyári associate professor, my supervisor for his support.

I express my sincere gratitude to Professor Dr. Ferenc Bari and Professor Dr. Zoltán Hantos for providing facilities to accomplish this thesis.

I express my gratitude to Professor Dr. László Nagymajtényi and Professor Dr. Jancsó Gábor for allowing me to participate in the Preventive Medicine Ph.D. Program.

I am grateful to Professor Dr. Erzsébet Nagy, Professor Dr. László Kovács for providing possibility to co-work with them.

Thanks to all colleagues at the Department of Medical Informatics for being supportive.

I am especially thankful to my wife for her patience and help.

The research partly was supported by the by the European Union and the State of Hungary, co-financed by the European Social Fund in the framework of TÁMOP4.2.2.A/11/1-KONV-2012-0073 'National Excellence Program' and TÁMOP-4.2.2.A11/1/KONV-2012-0052. I thank the contributors from all centres for their participation in this study. 


\section{REFERENCES}

1. Wang H, Liddell CA, Coates MM, Mooney MD, Levitz CE et al. Schumacher AE. Global, regional, and national levels of neonatal, infant, and under-5 mortality during 1990-2013: a systematic analysis for the Global Burden of Disease Study 2013. Lancet 2014; pii: S0140-6736(14)60497-9. doi: 10.1016/S0140-6736(14)60497-9.

2. Beck S, Wojdyla D, Say L, Betran AP, Merialdi M, Requejo JH, Rubens C, Menon R, Van Look PF. The worldwide incidence of preterm birth: a systematic review of maternal mortality and morbidity. Bull World Health Organ. 2010;88:31-8. doi: 10.2471/BLT.08.062554

3. M. C. McCormick, "The contribution of low birth weight to infant mortality and childhood morbidity," New England Journal of Medicine, vol. 312, no. 2, pp. 82-90, 1985

4. Organization for Economic Co-operation and Development. Health: Key Tables from OECD - ISSN 2075-8480. DOI:10.1787/inf-mort-table-2013-2-en http://www.keepeek.com/Digital-Asset-Management/oecd/social-issuesmigration-health/infant-mortality-2013-2_inf-mort-table-2013-2-en\#page1.

5. The Hungarian Central Statistical Office. Demographic Yearbook, 1963 - 2012. Budapest, KSH.

6. Avcı ME, Sanlıkan F, Celik M, Avcı A, Kocaer M, Göçmen A. Effects of maternal obesity on antenatal, perinatal and neonatal outcomes. J Matern Fetal Neonatal Med. 2014 Nov 11:1-4.

7. Shaw E, Roberts D, Connor PD. Prevalence and risk factors for Chlamydia in a rural pregnant population. J Fam Pract 1995;41:257-260.

8. Smith JR, Taylor-Robinson D. Infection due to Chlamydial trachomatis in pregnancy and the newborn. Bailliers Clin Obstet Gynaecol 1993;7:237-255.

9. Hammerschlag MR. Chlamydial and gonococcal infections in infants and children. Clin Infect Dis. 2011;53: Suppl 3:S99-102. doi: 10.1093/cid/cir699.

10. Aghaizu A, Reid F, Kerry S, Hay PE, Mallinson H, Jensen JS, Kerry S, Kerry S, Oakeshott P. Frequency and risk factors for incident and redetected Chlamydia trachomatis infection in sexually active, young, multi-ethnic women: a community based cohort study. Sex Transm Infect. 2014;90:524-528. doi: 10.1136/sextrans-2014-051607. 
11. The Hungarian Epidemiological Centre. Epi Info vol 8-20, 2001-2014, Budapest

12. Altman M, Vanpée M, Cnattingius S, Norman M. Neonatal morbidity in moderately preterm infants: a Swedish national population-based study. $J$ Pediatr 2011; 158:239-244.

13. Neto MT. Perinatal care in Portugal: effects of 15 years of a regionalized system. Acta Paediatr 2006; 95:1349-1352.

14. Treurniet HF, Boshuizen HC, Harteloh PP. Avoidable mortality in Europe (1980-1997): a comparison of trends. J Epidemiol Community Healt. 2004; 58:290-295.

15. Halberstaedter L. and Prowazek S, Zur Atiologie des Trachoms. Deutsch Med Wochensch. 1907;33:1285-1287.

16. Fritsch H, Hofstätter A, Lindner K. Experimentelle Studien zur Trachomfrage, Graefes Arch Ophthalmol. 1910;76:547-558.

17. Howick J, Cals JW, Jones C, Price CP, Plüddemann A, Heneghan C, Berger MY, Buntinx F, Hickner J, Pace W, Badrick T, Van den Bruel A, Laurence C, van Weert HC, van Severen E, Parrella A, Thompson M.Current and future use of point-of-care tests in primary care: an international survey in Australia, Belgium, The Netherlands, the UK and the USA. BMJ Open. 2014;4.:e005611. doi: 10.1136/bmjopen-2014-005611.

18. Thewessen EA, van der Meijden WI, Doppenberg HJ, Mulder PG, Wagenvoort JH, Stolz E, Michel MF. Screening for cervical Chlamydia trachomatis infections in two Dutch populations. Genitourin Med. 1990;66:361-366.

19. Washington AE, Katz P. Cost of and payment source for pelvic inflammatory disease: trends and projections, 1983 through 2000. JAMA. 1991;266:25652569.

20. Czeizel AE, Rockenbauer M. A lower rate of preterm birth after clotrimazole therapy during pregnancy. Paediatr Perinat Epidemiol 1999;13:58-64.

21. Orvos H, Nyirati I, Hajdú J, Pá Al, Nyári T and Kovács L. Is adolescent pregnancy associated with adverse perinatal outcome? J Perinat Med 1999;27:199-203.

22. Muh DH, Yeh SY. Relevance of Chlamydia trachomatis infection in pregnant patients. Public Health Rep. 1991;106:490-493.

23. Ngassa PC, Egbe JA. Maternal genital Chlamydia trachomatis infection and the risk of preterm labour. Int J Gynecol Obstet, 1994;57:241-246. 
24. Nyári T, Deák J, Nagy E, Veréb I, Kovács L, Mészáros Gy, Orvos H and Berbik I: Epidemiological study of Chlamydia trachomatis infection in pregnant women in Hungary. Sex Transm Inf, 1998;74:213-215.

25. Kovács L, Nagy E, Berbik I, Mészáros Gy, Deák J, Nyári T. The frequency and the role of Chlamydia trachomatis infection in premature labor. Int J Gynec Obst.1998;62:47-54.

26. Rogers, W. H. Regression standard errors in clustered samples. Stata Technical Bulletin 1993; 13:19-23.

27. Walter SD, Elwood JM. A test for seasonality of events with a variable population at risk. Br J Prev Soc Med 1975; 29:18-21.

28. Stolwijk AM, Straatman H, Zielhuis GA. Studying seasonality by using sine and cosine functions in regression analysis. J Epidemiol Community Health 1999; 53:235-238.

29. Newhall WJ, Johnson RE, DeLisle S, Fine D, Hadgu A, Matsuda B et al. Headto-head evaluation of five chlamydia tests relative to a quality-assured culture standard. J Clin Microbiol; 1999;37:681-685.

30. Rogan WJ and Gladen B: Estimating prevalence from the results of a screening test, Am J Epidem, 1978;107: 71-76.

31. Hsieh FY. Sample size tables for logistic regression. Stat Med, 1989;8: 795-802.

32. Decree of No 9/1993 of Hungarian Ministry of Health and Welfare. 1997. (In Hungarian)

33. Genç M, Mardh PA. A cost-effectiveness analysis of screening and treatment for Chlamydia trachomatis infection in asymptomatic women. Ann Intern Med 1996;124:1-7.

34. Sziller I, Ujhazy A, Bardoczy Z, Szendei G, Papp Z. Incidence and mortality of extrauterine pregnancy in Hungary (1931-1995) . Orv Hetil 1998;139:493-498.

35. Rappai Á, Krasznai P, Molnár Gy, Závody E Incidence of Chlamydia trachomatis infection by women during pregnancy and before labor, and newborns Orv Hetil 1995;136:1945-1948.

36. Stamm WE, Cole B. Asymptomatic Chlamydia trachomatis urethritis in men. Sex Transm Dis 1986;13:163-165.

37. Szirmai Z, Marton A, Kemeny J, Szever Z, Fodor M, Gal E. Neonatal pneumonia caused by Chlamydia trachomatis Orv Hetil 1985;126:1027-1030. 
38. Ngassa PC, Egbe JA. Maternal genital Chlamydia trachomatis infection and the risk of preterm labour. Int J Gynecol Obstet. 1994;57:241-246.

39. Westrom L, Joesoef R, Reynolds G Hagdu A, Thompson SE. Pelvic inflammatory disease and fertility. A cohort study of 1,844 women with laparoscopically verified disease and 657 control women with normal laparoscopic results. Sex Transm Dis. 1992;19:185-192.

40. Nyári Tibor, Deák Judit, Nyári Csaba, Mészáros Gyula. A Chlamydia trachomatis fertőzés gyakorisága és lehetséges rizikófaktorainak meghatározás epidemiológiai módszerekkel. XXI. Neumann Kollokvium Veszprém, 1998 167169.(in Hungarian)

41. Nyári T, Woodward M, Mészáros G, Karsai J, Kovács L. Chlamydia trachomatis infection and the risk of perinatal mortality in Hungary. $J$ Perinat Med. 2001;29:55-59.

42. Magid D, Douglas JM Jr, Schwartz JS. Doxycycline compared with azithromycin for treating women with genital Chlamydia trachomatis infections: an incremental cost-effectiveness analysis. Ann Intern Med 1996;124:389-399.

43. Petitti D.B. Meta-Analysis, decision analysis and cost-effectiveness analysis. Oxford University Press, Oxford, 1994.

44. Rüttimann D1, Loesch S. Mortality and morbidity in the city of Bern, Switzerland, 1805-1815 with special emphasis on infant, child and maternal deaths. Homo 2012; 63:50-66.

45. Ahle M1, Drott P, Andersson RE. Epidemiology and trends of necrotizing enterocolitis in Sweden: 1987-2009. Pediatrics.2013; 132:e443-451

46. Sidebotham P, Fraser J, Fleming P, Ward-Platt M, Hain R. Patterns of child death in England and Wales. Lancet 2014; 384(9946):904-914.

47. Kalder M, Reichelt J, Kyvernitakis I, Misselwitz B, Hadji P, Schmidt S.A Population-based study on trends in the mode of delivery subsequent to stillbirth, infant mortality and severe infant malformations in the state of Hesse, Germany between 1990 and 2012. Z Geburtshilfe Neonatol 2014; 218:113-121.

48. Regidor E, Santos JM, Ortega P, Calle ME, Astasio P, Martínez D . Decreasing income inequality and emergence of the association between income and premature mortality: Spain, 1970-2010. Health Place. 2014; 27:30-37. 
49. Lin CM, Chen CW, Chen PT, Lu TH, Li CY. Risks and causes of mortality among low-birthweight infants in childhood and adolescence. Paediatr Perinat Epidemiol 2007; 21:465-472.

50. Corchia C1, Orzalesi M. Geographic variations in outcome of very low birth weight infants in Italy. Acta Paediatr 2007; 96:35-38.

51. Nyári TA. Risk factors and trends in the rate of stillbirth in Hungary between 1971 and 2010. J Matern Fetal Neonatal Med 2014; 27:1195-1198.

52. Ko YJ, Shin SH, Park SM, Kim HS, Lee JY, Kim KH, Cho B. Effects of employment and education on preterm and full-term infant mortality in Korea. Public Health. 2014; 128:254-261.

53. Arntzen A, Mortensen L, Schnor O, Cnattingius S, Gissler M, Andersen AM. Neonatal and postneonatal mortality by maternal education- a population-based study of trends in the Nordic countries, 1981-2000. Eur J Public Health 2008; $18: 245-251$.

54. Devlieger H, Martens G, Bekaert A. Social inequalities in perinatal and infant mortality in the northern region of Belgium (the Flanders). Eur J Public Health $2005 ; 15: 15-19$.

55. Siffel C, Alverson CJ, Correa A. Analysis of seasonal variation of birth defects in Atlanta. Birth Defects Res A Clin Mol Teratol 2005; 73:655-662.

56. Hare EH, Moran PA, Macfarlane A. The changing seasonality of infant deaths in England and Wales 1912-78 and its relation to seasonal temperature. $J$ Epidemiol Community Health 1981; 35:77-82.

57. Ottóffy G, Szigeti E, Bartyik K, Nyári C, Parker L, McNally RJ, Nyári TA.Investigating the Relationship between Mortality from Respiratory Diseases and Childhood Acute Lymphoblastic Leukaemia in Hungary. Pathol Oncol Re. 2014 May 8

58. Handsfield HH, Jasman LL, Roberts PL, Hanson VW, Kothenbeutel RL, Stamm WE.: Criteria for selective screening for Chlamydia trachomatis infection in women attending family planning clinics. JAMA 1986;255:1730-1734.

59. Haddix AC, Hillis SD, Kassler WJ. The cost effectiveness of azithromycin for Chlamydia trachomatis infections in women. Sex Transm Dis 1995;22:274-80.

60. Howell MR, Quinn TC, Gaydos CA. Screening for Chlamydia trachomatis in asymptomatic women attending family planning clinics: a cost-effectiveness analysis of three strategies. Ann Intern Med 1998;128:277-284. 
61. Bashir SA, Duffy SW. Correction of risk estimates for measurement error in epidemiology. Meth Inform Med, 1995;34:503-10.

62. LIFESTAT 2008. First Conference of the Central European Network. Statistics and Life Sciences: Perspectives and Challenges 54. Biometrisches Kolloquium / 25. ROeS Seminar, March 10 - 13, 2008 ,University of Munich

63. Marrazzo JM, Celum CL, Hillis SD, Fine D, DeLisle S, Handsfield HH Performance and cost-effectiveness of selective screening criteria for Chlamydia trachomatis infection in women. Implications for a national Chlamydia control strategy. Sex Transm Dis 1997; 24:131-41.

64. Gershman-KA; Barrow-JC. A tale of two sexually transmitted diseases. Prevalences and predictors of chlamydia and gonorrhea in women attending Colorado family planning clinics. Sex Transm Dis. 1996;23:481-488

65. Scholes D, Stergachis A, Heidrich FE, Andrilla H, Holmes KK, Stamm WE. Prevention of pelvic inflammatory disease by screening for cervical chlamydial infection. N Engl J Med 1996;334:1362-6.

66. Weinstock HS, Bolan GA, Kohn R, Balladares C, Back A, Oliva G. Chlamydia trachomatis infection in women: a need for universal screening in high prevalence populations? Am J Epidemiol 1992;135:41-7.

67. Sellors JW, Pickard L, Gafni A, Goldsmith CH, Jang D, Mahony JB, Chernesky MA. Effectiveness and efficiency of selective vs universal screening for chlamydial infection in sexually active young women. Arch Intern Med. 1992;152:1837-44.

68. Oakeshott P1, Kerry S, Aghaizu A, Atherton H, Hay S, Taylor-Robinson D, Simms I, Hay P.Randomised controlled trial of screening for Chlamydia trachomatis to prevent pelvic inflammatory disease: the POPI (prevention of pelvic infection) trial.BMJ. 2010 Apr 8;340:c1642. doi: 10.1136/bmj.c1642.

69. Cheney K1, Wray L. Chlamydia and associated factors in an under 20s antenatal population. Aust N Z J Obstet Gynaecol. 2008;48:40-3. doi: 10.1111/j.1479828X.2007.00802.x.

70. Field N, Kennedy I, Folkard K, Duffell S, Town K, Ison CA, Hughes G. Screening for gonorrhoea using samples collected through the English National Chlamydia Screening Programme and risk of false positives: a national survey of Local Authorities. BMJ Open. 2014 16;4(10):e006067. doi: 10.1136/bmjopen-2014-006067. 
71. Jackson LJ, Auguste P, Low N, Roberts TE.Valuing the health states associated with Chlamydia trachomatis infections and their sequelae: a systematic review of economic evaluations and primary studies. Value Health. 2014 JanFeb;17(1):116-30. doi: 10.1016/j.jval.2013.10.005. Review.

72. Ancel PY, MJ Saurel-Cubizolles, GC Di Renzo, E. Papiernik, G Breart and the EUROPOP Group: Social differences of very preterm birth in Europe: Interaction with obstetric history Am J Epidem 1999;149: 908-915. 